\title{
COMPORTAMENTO DE UM MOTOR DE IGNIÇÃO POR COMPRESSÃO TRABALHANDO COM ÓLEO DIESEL E GÁS NATURAL ${ }^{1}$
}

\author{
JOSÉ F. SCHLOSSER ${ }^{2}$, MIGUEL N. CAMARGO ${ }^{3}$, PAULO R. M. MACHADO ${ }^{4}$
}

\begin{abstract}
RESUMO: A previsível escassez de petróleo aliada a uma consciência ecológica está levando pesquisadores a procurar novas fontes de energia e processos de combustão mais eficientes e menos poluentes. Entre os combustíveis menos poluentes está o gás natural, cujo consumo aumenta ano a ano. Os motores de combustão interna são transformadores de energia que têm baixa eficiência de conversão. Este trabalho avaliou um motor Diesel, bicombustível, movido a Diesel e gás natural. Nesse motor, a energia provém, basicamente, da combustão do gás natural. O Diesel tem a função de produzir o início da combustão do gás, que é o combustível principal. Assim, haverá uma substituição parcial de óleo Diesel por gás natural, aumentando o rendimento da combustão. Inicialmente, foi feito um ensaio-testemunha, somente com óleo Diesel e após foram feitos ensaios, com três repetições, para variadas proporções de óleo Diesel, gás natural e ângulos de avanço da injeção. O melhor desempenho foi obtido para $22 \%$ de óleo Diesel em relação ao máximo débito da bomba injetora e $13 \mathrm{~L} \mathrm{~min}^{-1}$ de gás natural com ângulo de avanço de injeção original $\left(21^{\circ}\right)$. Nesse caso, a potência média aumentou $14 \%$, e o consumo específico (medido em valores monetários) diminuiu $46 \%$ em relação ao ensaiotestemunha.
\end{abstract}

PALAVRAS-CHAVE: motor bicombustível, motor Diesel, gás natural.

\section{A DUAL FUEL COMPRESSION IGNITION ENGINE PERFORMANCE, RUNNING WITH DIESEL FUEL AND NATURAL GAS}

SUMMARY: The foresight of a petroleum shortage and an ecological conscience is moving scientists to look for new sources of energy and to develop more efficient combustion processes and reduced emissions. Natural gas is a reduced emission fuel, whose consumption increases every year. The present work evaluates a dual fuel compression ignition engine. The major portion of the fuel burned is natural gas. The Diesel fuel acts as combustion starter, which ignites under the compression heat. Diesel fuel is used only as an ignition source. The partial substitution of Diesel fuel by natural gas increases the combustion efficiency and achieves significant emission reduction, because the combustion of natural gas produces less emission than the combustion of Diesel fuel. Initially, it was made a reference test using only Diesel fuel for comparison with following tests. There were made tests with varied proportions of Diesel fuel and natural gas, and with variable injection angles. There were made three repetitions for each test, including the reference test. The best performance was obtained with $22 \%$ of Diesel fuel and $13 \mathrm{~L} \mathrm{~min}^{-1}$ of natural gas, and with the engine original injection angle $\left(21^{\circ}\right)$. In this case, the average power was $14 \%$ above the standard engine and the cost of consumption was $46 \%$ lower than the reference test.

KEYWORDS: dual fuel engine, Diesel engine, natural gas.

\footnotetext{
${ }^{1}$ Extraído da Dissertação de mestrado do segundo autor

2 Eng ${ }^{\circ}$ Agrônomo, Prof. Titular, Departamento de Engenharia Rural, CCR, UFSM, Santa Maria - RS, Fone: (0XX55) 220.8175, e-mail: schlosse@ccr.ufsm.br

${ }^{3}$ Eng ${ }^{\mathrm{o}}$ Mecânico, Aluno do Programa de Pós-Graduação em Engenharia Agrícola, CCR, UFSM, Santa Maria - RS.

${ }^{4}$ Eng ${ }^{\mathrm{O}}$ Mecânico, Prof. Assistente, Departamento de Termotécnica, Processos e Operações Industriais, CT, UFSM, Santa Maria - RS.

Recebido pelo Conselho Editorial em: 13-5-2003

Aprovado pelo Conselho Editorial em: 26-7-2004
} 


\section{INTRODUÇÃO}

A partir da década de 1970, o governo brasileiro começou a tomar medidas para reduzir a dependência de petróleo importado do Oriente Médio. Entre as medidas adotadas, mais recentemente encontra-se a alternativa do gás natural; um combustível menos poluente, de baixo custo e abundante que pode substituir com vantagens outros combustíveis oriundos do petróleo em quase todas as aplicações, inclusive para alimentar motores alternativos de combustão interna. Hoje, uma frota significativa de táxis e mesmo de carros particulares é movida a gás natural nas principais capitais do País. O gás natural tem um índice de octanas muito elevado, podendo chegar a 140 octanas. Índice de octanas, segundo GIACOSA (1986), é um índice empírico que mede a capacidade de uma mistura estequiométrica de um combustível com ar, de suportar a pressões elevadas sem entrar em combustão espontânea. Já o índice de cetano, segundo GIACOSA (1986), é um índice empírico que mede a facilidade de um combustível queimar espontaneamente na presença de ar quando submetido à pressão elevada. Nos motores de ignição por compressão (motores Diesel), a combustão ocorre espontaneamente devido à alta pressão a que fica submetido o ar, na câmara de combustão, onde o combustível Diesel é injetado. Portanto, se um motor Diesel for alimentado apenas por gás natural, não haverá combustão porque o gás natural tem um elevado índice de octanas e, portanto, suporta a elevada taxa de compressão sem entrar em combustão. Isso configura um problema: um motor de ignição por compressão, em condições normais, não funciona com gás natural.

Para resolver esse problema, pode ser adotada como solução um motor bicombustível. TAYLOR (1971) afirma que motor bicombustível é aquele que trabalha simultaneamente com dois combustíveis e, em geral, são motores Diesel que trabalham com óleo Diesel e outro combustível que pode ser gasoso ou líquido vaporizado. Nesse caso, o gás ou vapor é introduzido juntamente com o ar na fase de admissão, e a ignição é efetuada por uma pequena injeção-piloto de Diesel. Segundo OBERT (1971), nesses motores, o óleo Diesel continua sendo usado normalmente, porém apenas como combustívelpiloto para proporcionar a ignição por compressão, dando início à combustão do combustível principal (gás ou líquido vaporizado) que é admitido no cilindro pelo coletor de admissão, semelhante à alimentação de um motor de ciclo Otto, mas com mistura pobre. Esse sistema apresenta a vantagem de não exigir modificações no motor.

BHATTACHRYA et al. (1988) testaram um motor Diesel agrícola trabalhando em regime bicombustível, sendo biogás e óleo Diesel, e concluíram que um motor de ignição por compressão pode trabalhar facilmente em regime bicombustível e que cerca de $70 \%$ do óleo Diesel pode ser substituído por biogás. DE ZANCHE (1989) testou um trator em regime bicombustível usando biogás como combustível principal e obteve cerca de 50\% de economia no consumo de óleo Diesel. SILVA (1999) testou um trator bicombustível trabalhando com metano e óleo Diesel em diversas operações normais de um trator e obteve de $70 \%$ a $80 \%$ de redução no consumo do óleo Diesel.

O objetivo deste trabalho foi testar um motor Diesel trabalhando em regime bicombustível com óleo Diesel e gás natural. O ensaio foi realizado em um dinamômetro hidráulico dotado de um sistema de aquisição de dados em tempo real. Foi medido o consumo dos dois combustíveis, sendo traçadas as curvas de torque, potência e consumo específico para variadas proporções de óleo Diesel e Gás natural e ângulo de avanço da injeção. Foram feitas análises entre as curvas obtidas para determinar quais as melhores condições de funcionamento do motor.

\section{MATERIAL E MÉTODOS}

Para a execução do experimento, foi testado um motor Diesel, marca Agrale, modelo M90, de injeção indireta, com torque máximo nominal de $35,58 \mathrm{Nm}$ e potência máxima nominal de $8,8 \mathrm{~kW}$ $(12 \mathrm{cv})$. Esse motor foi ensaiado com máxima aceleração e variação de torque em um dinamômetro de absorção hidráulica, fabricado pela empresa Motorpower, modelo $800 \mathrm{~V}$, dotado de um sistema de 
aquisição de dados computadorizado. O programa computacional de interpretação dos resultados, disponível, apresenta curvas de potência e torque, além de planilhas com os dados obtidos. Sobre esses dados, foram calculados e aplicados os índices de correção da potência, de acordo com a prescrição da norma brasileira NBR 5484 (ABNT, 1985), em função das condições atmosféricas no momento do ensaio.

Tomaram-se apenas os valores indicados de força aplicada diretamente no ponto de apoio do braço de alavanca do dinamômetro, que, multiplicados pelo comprimento dessa alavanca, passam a ser valores de torque instantâneo do motor. Como foram estabelecidos intervalos de rotação de 50 em $50 \mathrm{rpm}$, variando entre os limites de 1.800 e $2.800 \mathrm{rpm}$, pôde-se montar uma planilha com os dados de torque e, conseqüentemente, de potência para cada faixa de rotação do motor.

Para determinar o consumo específico do motor, foram adotados dois métodos (direto e indireto) que, confrontados, apresentaram valores equivalentes. Pelo método direto, o consumo de combustível foi determinado colocando-se o Diesel em uma proveta instalada sobre uma balança de precisão. Essa proveta era dotada de uma saída inferior que alimentava o motor de combustível. Com o motor em funcionamento constante, a uma determinada rotação e para um determinado torque, estabelecia-se um intervalo de tempo cronometrado. No início desse intervalo, a balança era zerada, e, ao final do mesmo, a pesagem era interrompida, assim podia-se determinar a quantidade de combustível consumida em um intervalo de tempo conhecido, para uma potência constante, em determinada rotação. No método direto, foi coletado e pesado o combustível realmente injetado pelo bico injetor. O bico injetor foi retirado do motor, mas foi mantida a sua conexão com a bomba injetora. $\mathrm{O}$ motor foi acionado por meio de uma manivela, sem funcionar. $\mathrm{O}$ bico injetor foi introduzido dentro de uma proveta na qual o combustível injetado era coletado e pesado. Para facilitar a pesagem, dada a pequena quantidade injetada a cada ciclo, era coletado o combustível injetado em 100 movimentos de injeção. Assim, foi determinado o máximo débito da bomba injetora e as posições da alavanca do acelerador para as quais se obtiveram os percentuais de injeção de óleo Diesel empregado nos ensaios.

Para determinar o consumo de gás natural, foi utilizado um fluxômetro do tipo tubo cônico e esfera flutuante (rotâmetro) descrito por DELMÉE (1995). O referido fluxômetro foi aferido para ser usado com gás natural. Para fazer a aferição, foi utilizado um método prático, pelo qual foi medido, sob pressão atmosférica, o volume de gás que passou pelo fluxômetro durante um tempo conhecido. $\mathrm{O}$ recipiente usado para coletar o gás a ser medido foi um tubo de filme de polietileno de pouca espessura, tal que, o seu peso próprio não causasse deformações significativas na secção transversal do tubo. Foi usada uma coluna manométrica para controlar a pressão interna no tubo, evitando que essa ultrapassasse a pressão atmosférica. O tubo era inflado com gás durante um intervalo de tempo medido, mantendo-se uma vazão predeterminada constante, indicada pelo fluxômetro.

Para facilitar a execução dos ensaios, foi necessário retirar do motor os contrapesos do mecanismo limitador da rotação. Esse mecanismo de contrapesos centrífugos age cortando a injeção de combustível caso a rotação do motor ultrapasse a rotação predeterminada pela posição da alavanca do acelerador. Em um motor bicombustível, a aceleração em Diesel deve ser fixada em um valor pequeno e complementada pelo gás natural. Se fosse conservado em funcionamento o mecanismo limitador de rotação, com a adição de gás natural, a rotação do motor seria maior que a rotação preestabelecida pela posição da alavanca do acelerador, conseqüentemente o mecanismo limitador de rotação iria agir cortando a injeção de combustível Diesel. Assim, o motor não funcionaria por falta da fonte de ignição que é a injeção-piloto de Diesel.

No cálculo do consumo específico, determinou-se o consumo de óleo Diesel $\left(\mathrm{g} \mathrm{kWh}^{-1}\right)$ e o consumo de gás natural $\left(\mathrm{L} \mathrm{kWh}^{-1}\right)$. Para determinar o consumo específico total, foi necessário converter ambos os consumos para uma mesma unidade. Para tanto, foi determinado um consumo de 
Diesel equivalente, em energia, ao consumo de gás natural. Assim, os dois consumos puderam ser somados e transformados em valores monetários na data dos ensaios.

Foram consideradas como variáveis independentes o ângulo de avanço de injeção, com valores de $21^{\circ}$ (original de fábrica) e $24^{\circ}$; a porcentagem de aceleração de combustível Diesel em relação à posição da alavanca do acelerador que determina o máximo débito da bomba injetora, com valores de $100 \% ; 60 \% ; 40 \% ; 30 \% ; 22 \% ; 14 \%$ e $5 \%$, e a vazão de gás natural, com valores de $3 \mathrm{~L} \mathrm{~min}^{-1} ; 5 \mathrm{~L} \mathrm{~min}^{-1}$; $7 \mathrm{~L} \mathrm{~min}^{-1} ; 9 \mathrm{~L} \mathrm{~min}^{-1} ; 11 \mathrm{~L} \mathrm{~min}^{-1} ; 13 \mathrm{~L} \mathrm{~min}^{-1}$ e $15 \mathrm{~L} \mathrm{~min}^{-1}$. As porcentagens de óleo Diesel foram definidas como um porcentual do débito da bomba injetora para a máxima aceleração do motor trabalhando somente com óleo Diesel. Ou seja, um porcentual da aceleração máxima do motor, quando funcionando somente com Diesel. Para cada ensaio, foi fixada a aceleração da bomba injetora conforme o percentual escolhido, acima definido. Dessa forma, como o débito da bomba é constante para cada ciclo de injeção, a variação do consumo de óleo Diesel é função da rotação do motor. Para o gás natural, foi mantida uma vazão constante predeterminada, independentemente da rotação do motor, ajustada por uma válvula reguladora e medida por um fluxômetro.

Os ensaios foram definidos pela combinação das variáveis independentes e para cada ensaio, foram feitas três repetições. Como variáveis dependentes, foram definidos torque, potência e consumo específico.

Os dados obtidos de torque, potência e consumo específico, para cada faixa de rotação, assim como dados extras de temperaturas do motor fornecidos pelo dinamômetro, além dos parâmetros de cálculo dos itens anteriores, foram listados, para cada repetição, em uma planilha que serviu de base para a análise dos resultados.

\section{RESULTADOS E DISCUSSÃO}

Foram aplicados métodos estatísticos para analisar e interpretar os resultados dos experimentos executados. Foi utilizado o sistema computacional Statistical Analysis Systems (SAS) e foi aplicado primeiramente um teste de normalidade, teste de Sapiro-Wilk, para saber se a distribuição dos resultados obtidos seguia uma distribuição normal. Como ficou determinado por esse teste que a distribuição não era normal, foi adotada a análise de variância não-paramétrica. Optou-se pelas provas de Wilcoxon e de Kruzkal-Wallis.

Pela prova de Wilcoxon, ficou comprovado que a maior média dos escores foi apresentada pelo grupo de ensaios com $22 \%$ de óleo Diesel e para o grupo de ensaios com $13 \mathrm{~L} \mathrm{~min}^{-1}$ de gás natural, conforme pode ser verificado nas Tabelas 1 e 2, exemplificado na variável dependente potência.

TABELA 1. Análise de Wilcoxon para o grupo porcentagem de aceleração de Diesel e variável dependente potência.

\begin{tabular}{crrrr}
\hline Variável da Porcentagem de & \multirow{2}{*}{$\mathrm{N}$} & Desvio-Padrão & \multicolumn{2}{c}{ Escores } \\
\cline { 4 - 5 } Diesel (\%) & & & \multicolumn{1}{c}{ Soma } & Média \\
\hline 5 & 378 & $11.825,28$ & 144.994 & 383,58 \\
14 & 420 & $12.328,28$ & 407.254 & 969,65 \\
22 & 642 & $14.315,96$ & 1.007 .071 & $1.568,64$ \\
30 & 315 & $10.970,09$ & 400.699 & $1.272,06$ \\
40 & 252 & $9.966,13$ & 295.894 & $1.174,18$ \\
60 & 234 & $9.645,63$ & 331.810 & $1.417,99$ \\
100 & 63 & $5.207,49$ & 67.636 & $1.073,59$ \\
\hline
\end{tabular}


TABELA 2. Análise de Wilcoxon para o grupo vazão de gás e variável dependente potência.

\begin{tabular}{cccrr}
\hline \multirow{2}{*}{$\begin{array}{c}\text { Vazão de Gás } \\
\left(\mathrm{L} \mathrm{min}^{-1}\right)\end{array}$} & $\mathrm{N}$ & Desvio-Padrão & \multicolumn{2}{c}{ Escores } \\
\cline { 4 - 5 } & & & Soma & Média \\
\hline 0 & 315 & $10.9707,58$ & 143.199 & $2.273,00$ \\
5 & 420 & $12.328,48$ & 269.270 & 854,82 \\
7 & 441 & $12.562,33$ & 389.904 & 928,34 \\
9 & 423 & $12.362,58$ & 457.630 & $1.037,71$ \\
11 & 309 & $10.881,66$ & 493.059 & $1.165,62$ \\
13 & 177 & $8.503,84$ & 378.821 & $1.225,95$ \\
15 & 156 & $8.022,76$ & 276.017 & $1.559,42$ \\
& & & 247.458 & $1.586,27$ \\
\hline
\end{tabular}

Já a prova de Kruzkal-Wallis foi aplicada para determinar se havia diferenças significativas entre o ensaio-testemunha (100\% Diesel) e os demais ensaios. Nessa prova, foi considerado um nível de significância de 5\%. A hipótese de nulidade $\left(\mathrm{H}_{0}\right)$ afirma que não há diferença significativa entre ensaios. Foi aplicada a prova de Kruzkal-Wallis para os grupos formados, reunindo-se todos os ensaios com mesma porcentagem de aceleração de óleo Diesel e comparados em relação ao ensaiotestemunha. Da mesma forma, o teste foi aplicado também para os grupos formados pela reunião de todos os ensaios com mesma vazão de gás natural e comparados em relação ao ensaio-testemunha. Também foi feita a comparação dos grupos da variável independente ângulo de avanço da injeção em relação ao ensaio-testemunha. Os resultados da aplicação da prova de Kruzkal-Wallis indicam que existem diferenças significativas entre os ensaios e o ensaio-testemunha.

Para determinar a magnitude das diferenças apontadas nos testes estatísticos, foi empregada uma análise em que cada ensaio composto por três repetições teve traçadas as curvas de tendência para torque, potência e consumo específico, inclusive para o ensaio-testemunha. As curvas de tendência foram agrupadas em famílias. As curvas dos melhores ensaios foram selecionadas e reagrupadas, determinando-se as melhores. Para compor as famílias de curvas, primeiramente foram criados dois grandes grupos em função da variável independente ângulo de avanço da injeção. Após, foi feita uma subdivisão agrupando todas as curvas com mesmo ângulo de avanço de injeção e separando as variáveis dependentes torque, potência e consumo específico. Na Figura 1, apresentam-se as curvas dos ensaios-testemunha que serviram de comparação com todos os demais ensaios.

Os melhores ensaios obtidos estão representados nas Figuras 2; 3 e 4. Esses três ensaios apresentaram valores de torque e potência bastante superiores ao ensaio-testemunha e também valores de consumo específico bastante inferiores ao ensaio-testemunha, conforme pode ser visto na Tabela 1.

Os valores de porcentagem de Diesel, indicado nas Figuras seguintes, representam a porcentagem da aceleração máxima do motor caso estivesse trabalhando somente com Diesel. 


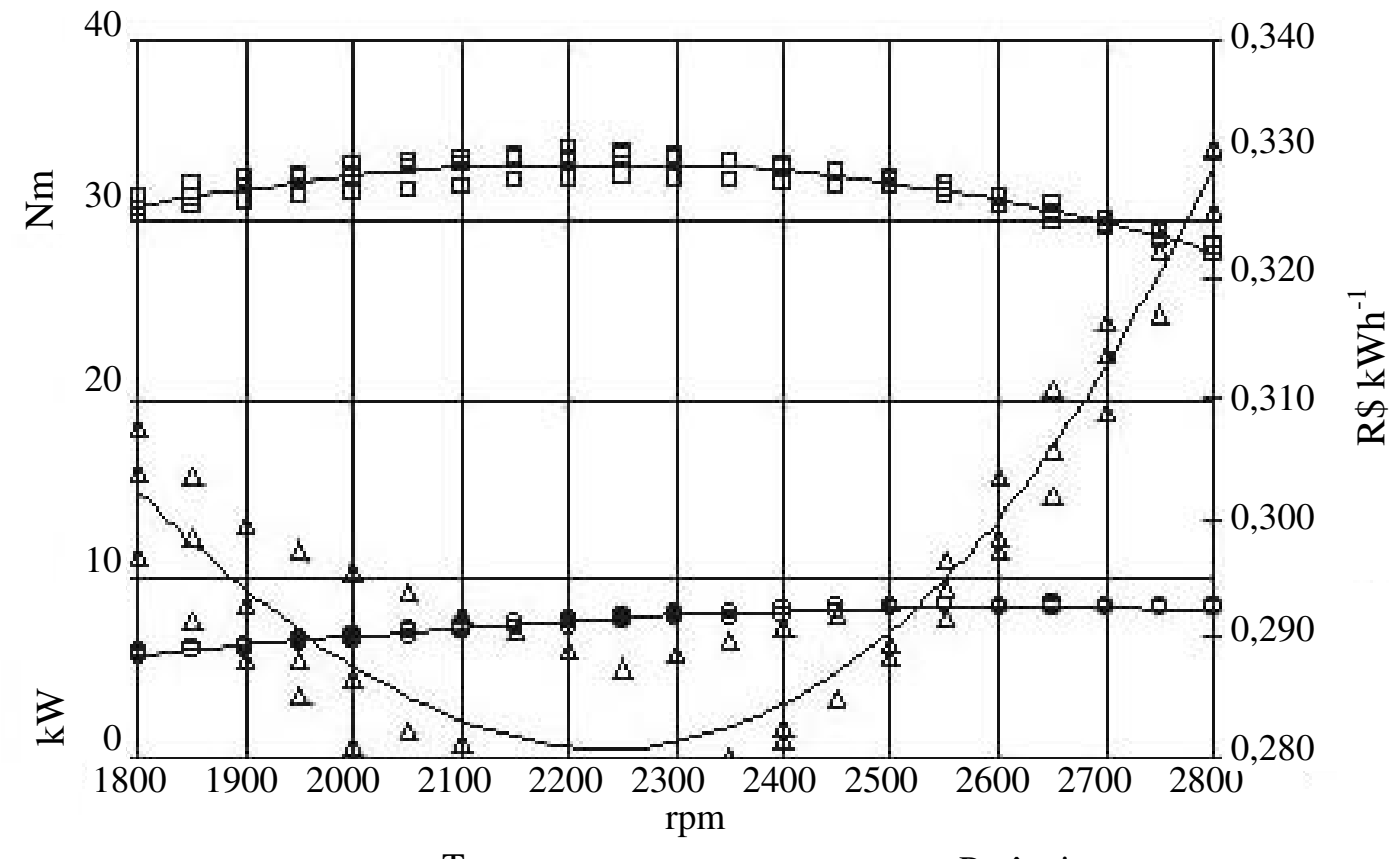

Torque

○ Potência

$\Delta$ Consumo

FIGURA 1. Curvas de desempenho do motor em torque $(\mathrm{Nm})$, potência $(\mathrm{kW})$ e consumo específico $\left(\mathrm{R} \$ \mathrm{kWh}^{-1}\right)$ para o ensaio-testemunha (100\% de Diesel).
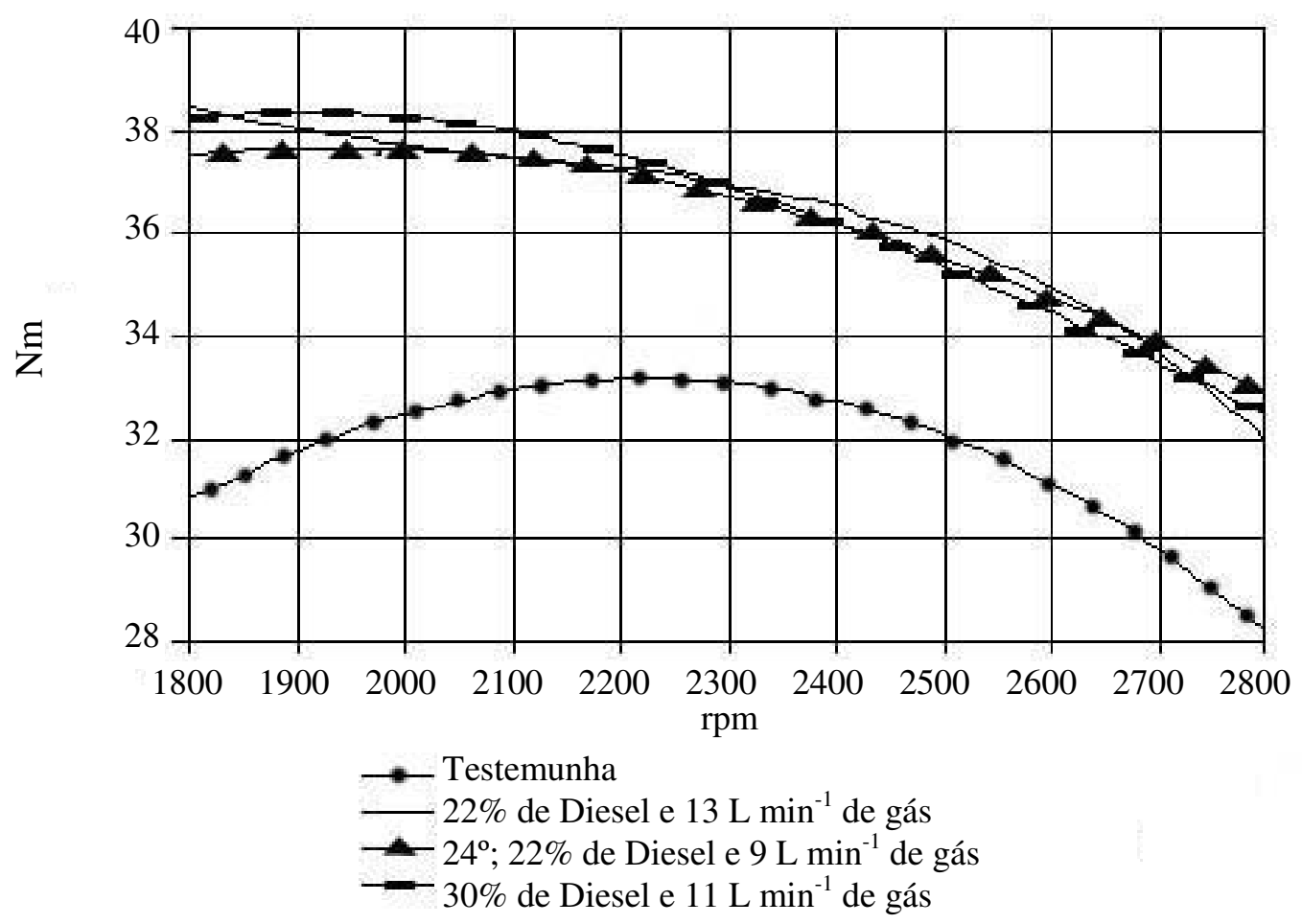

FIGURA 2. Comparação entre as curvas dos ensaios que apresentaram os melhores resultados de torque e o torque do ensaio-testemunha. 


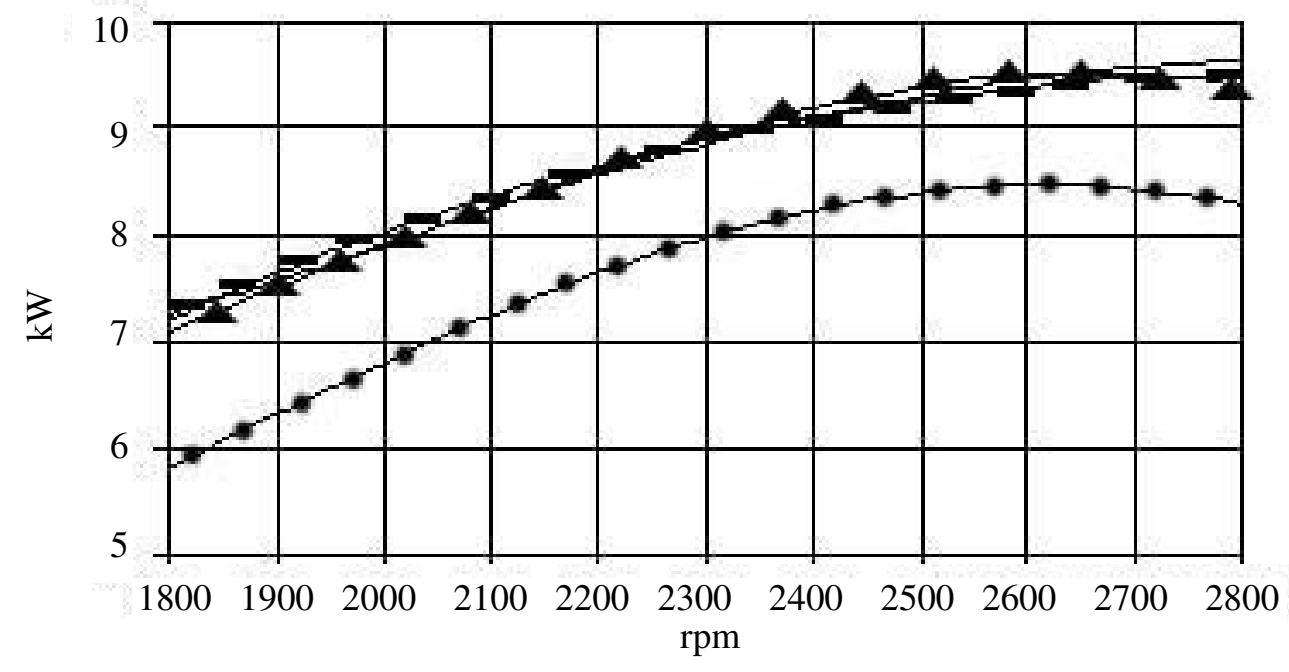

$\rightarrow-$ Testemunha

— $22 \%$ de Diesel e $13 \mathrm{~L} \mathrm{~min}^{-1}$ de gás

- $30 \%$ de Diesel e $11 \mathrm{~L} \mathrm{~min}^{-1}$ de gás

- $24^{\circ} ; 22 \%$ de Diesel e $9 \mathrm{~L} \min ^{-1}$ de gás

FIGURA 3. Comparação entre as curvas dos ensaios que apresentaram os melhores resultados de potência e a potência do ensaio-testemunha.

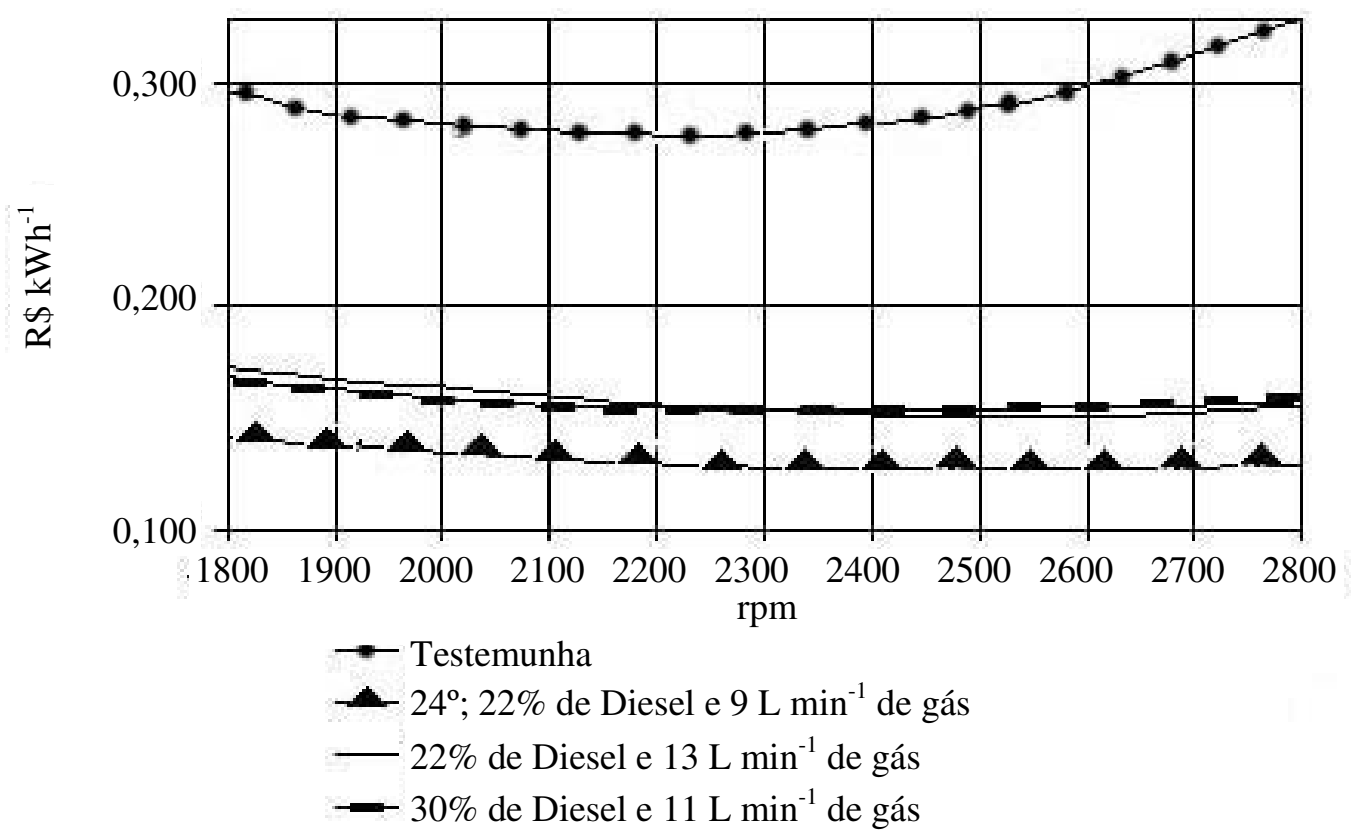

FIGURA 4. Comparação entre as curvas de consumo específico dos ensaios que apresentaram os melhores resultados torque e potência e o consumo específico do ensaio-testemunha.

O código de identificação dos ensaios tem o seguinte significado: D22g13a21, em que, D22 significa $22 \%$ da aceleração máxima da bomba injetora de Diesel; g13 significa $13 \mathrm{~L} \mathrm{~min}^{-1}$ de gás, e a21 significa ângulo de avanço da injeção igual a $21^{\circ}$.

Como pode ser visto na Tabela 1, os valores de torque médio dos três ensaios são muito semelhantes entre si, com diferenças inferiores a 5\%. Da mesma forma, os valores de potência média 
também são semelhantes, com diferenças inferiores a 5\%. Nos três ensaios, houve acréscimo de torque e de potência de aproximadamente $14 \%$ em relação ao ensaio-testemunha. As curvas de torque apresentaram valores mais elevados nas baixas rotações.

TABELA 1. Comparação dos melhores ensaios em relação ao ensaio-testemunha.

\begin{tabular}{lcccc}
\hline & Testemunha & \multirow{2}{*}{ D22g13a21 } & D30g11a21 & D22g9a24 \\
\hline Torque médio $(\mathrm{Nm})$ & \multirow{2}{*}{31,76} & 36,34 & 36,36 & 36,20 \\
Acréscimo de torque & \multirow{2}{*}{7,63} & $14,40 \%$ & $14,48 \%$ & $13,96 \%$ \\
\hline Potência média $(\mathrm{kW})$ & & 14,70 & 8,70 & 8,67 \\
Acréscimo de potência & \multirow{2}{*}{0,294} & 0,156 & $14,06 \%$ & $13,70 \%$ \\
\hline Consumo médio $\left(\mathrm{R} \$ \mathrm{kWh}^{-1}\right)$ & & $-46,87 \%$ & $-46,57 \%$ & 0,131 \\
Redução do consumo & & & \\
\hline
\end{tabular}

Para determinar os valores médios de torque, potência e consumo, foram feitas as médias das leituras obtidas para cada faixa de rotação pré-selecionadas para as três repetições de cada ensaio.

Os três ensaios, considerados melhores, apresentaram consumo específico bastante inferior ao consumo específico do ensaio-testemunha. O consumo mais baixo foi o do ensaio d22g9a24, com $55,31 \%$ de redução. Os outros dois ensaios apresentaram uma redução de cerca de $46 \%$ em relação ao ensaio-testemunha.

$\mathrm{Na}$ análise do consumo específico, não foram considerados os ensaios que apresentaram os menores valores absolutos de consumo, mas somente aqueles que apresentaram os melhores resultados de torque e potência. $\mathrm{O}$ ensaio $\mathrm{d} 22 \mathrm{~g} 9 \mathrm{a} 24$ apresentou valores de torque e potência aproximadamente iguais aos outros dois ensaios e consumo específico aproximadamente $10 \%$ inferior a esses, $\operatorname{logo}$, deveria ser considerado o melhor ensaio; entretanto, para esse ensaio, devido às modificações no ângulo de avanço da injeção, o motor não apresentou boa regularidade no funcionamento. $\mathrm{O}$ motor apresentou dificuldades para partir e para manter o funcionamento em determinadas rotações. Também mostrou grande dificuldade para funcionar em diferentes proporções de Diesel e gás natural. Por essa razão, só foram executados os ensaios com $22 \%$ de Diesel e, mesmo com essa porcentagem de Diesel, só foi possível completar toda a faixa de rotações para vazão de gás não superior a $9 \mathrm{~L} \mathrm{~min}^{-1}$. Dessa forma, só serão considerados como melhores os ensaios com ângulo de avanço de injeção normal de fábrica, ou seja, $21^{\circ}$.

Os ensaios de $21^{\circ}$ de avanço da injeção são d22g13a21 e d30g11a21. Esses ensaios são praticamente idênticos, tanto em torque e potência como em consumo específico. Do ponto de vista do motor, o melhor ensaio é o d30g11a21, porque, com 30\% de Diesel, o bico injetor se mantém mais frio, garantindo maior durabilidade ao mesmo. Segundo GIACOSA (1986), maior vazão do bico injetor ajuda a mantê-lo menos aquecido. Do ponto de vista ambiental, o melhor ensaio é o d22g13a21, pois, com menos Diesel, a poluição deverá ser menor, já que o Diesel tem em sua composição um volume de contaminantes bastante superior ao gás natural.

\section{CONCLUSÕES}

Nas condições em que foram realizados os ensaios e baseado nos resultados obtidos, pode-se concluir que é viável o uso de gás natural em motores Diesel, desde que, em regime bicombustível.

No motor ensaiado, houve acréscimo nos valores de torque e potência e redução de consumo específico, expresso em $\mathrm{R} \$ \mathrm{kWh}^{-1}$. Os melhores resultados foram obtidos para $22 \%$ de Diesel com $13 \mathrm{~L} \mathrm{~min}^{-1}$ de gás e $30 \%$ de Diesel com $11 \mathrm{~L} \mathrm{~min}^{-1}$ de gás. Nestes ensaios, obtiveram-se potência e 
torque $14 \%$ superiores ao ensaio-testemunha, quando o motor funcionou somente com Diesel, e $46 \%$ de redução do consumo específico, expresso em $\mathrm{R} \$ \mathrm{kWh}^{-1}$, em relação ao mesmo ensaio-testemunha.

Os ensaios feitos com alteração do ângulo de avanço da injeção, em geral, não apresentaram boa regularidade de funcionamento.

\section{REFERÊNCIAS}

ASSOCIAÇÃO BRASILEIRA DE NORMAS TÉCNICAS. NBR 5484: motores alternativos de combustão interna de ignição por compressão (Diesel) ou ignição por centelha (Otto) de velocidade angular variável - ensaio - Método de ensaio. Rio de Janeiro, 1985. 8 p.

BHATTACHARYA, T.K.; BACHCHAN, S.; MISHRA, T.N. A compression ignition engine on biogas-Diesel fuel. Agricultural Mechanization in Asia, Africa and Latin America, Tóquio, v.19, n.3, p.32-6, 1988.

DELMÉE, G.J. Manual de medição de vazão. 2.ed. São Paulo: Edgard Blücher, 1995. 476 p.

DE ZANCHE, C.; FRISO, F. La trattice a biogás è ormai una realta. Macchine \& Mottore Agricoli, Bologna, v.2, n.2, p.23-9, 1989.

GIACOSA, D. Motores endotérmicos. Madrid: Editorial Dossat, 1986. 722 p.

OBERT, E.F. Motores de combustão interna. Porto Alegre: Globo, 1971. 618 p.

SILVA, F.M.; SALVADOR, N.; SANTOS, A.M. Desempenho de um trator acionado a duplo combustível - metano e Diesel. Lavras: Universidade Federal de Lavras, 1999. 6 p.

TAYLOR, C.F. Análise dos motores de combustão interna. São Paulo: Edgard Blücher, 1971. 558 p. 